\title{
Results of redo pulmonary metastasectomy
}

\author{
Vincenzo Ambrogi ${ }^{1}$, Alessandro Tamburrini ${ }^{2}$, Riccardo Tajé ${ }^{3}$ \\ ${ }^{1}$ Thoracic Surgery Unit, Tor Vergata University Polyclinic, Rome, Italy; ${ }^{2}$ Thoracic Surgery Unit, Southampton University Hospital, Southampton, \\ UK; ${ }^{3}$ Tor Vergata University School of Medicine, Rome, Italy \\ Contributions: (I) Conception and design: V Ambrogi, R Tajè; (II) Administrative support: V Ambrogi; (III) Provision of study materials or patients: R \\ Tajè; (IV) Collection and assembly of data: V Ambrogi, R Tajè; (V) Data analysis and interpretation: V Ambrogi, R Tajè; (VI) Manuscript writing: All \\ authors; (VII) Final approval of manuscript: All authors. \\ Correspondence to: Vincenzo Ambrogi. UOC di Chirurgia Toracica, Policlinico Università di Roma Tor Vergata, Viale Oxford 81, 00133 Rome. Italy. \\ Email: ambrogi@med.uniroma2.it.
}

\begin{abstract}
Repeat surgical resection (redo) for pulmonary metastases is a questionable, albeit intriguing topic. We performed an extensive review of the literature, to specifically analyze results of redo pulmonary metastasectomies. We reviewed a total of 3,523 papers. Among these, 2,019 were excluded for redundancy and 1,105 because they were not completely retrievable. Out of 399 eligible papers, 183 had missing information or missing abstract, while 96 lacked data on survival. A total of 120 papers dated from 1991 onwards were finally included. Data regarding mortality, major morbidity, prognostic factors and long-term survivals of the first redo pulmonary metastasectomies were retrieved and analyzed. Homogeneity of data was affected by the lack of guidelines for redo pulmonary metastasectomy and the risks of bias when comparing different studies has to be considered. According to the histology sub-types, redo metastasectomies papers were grouped as: colorectal $(n=42)$, sarcomas $(n=36)$, others $(n=20)$ and all histologies $(n=22)$; the total number of patients was 3,015. Data about chemotherapy were reported in half of the papers, whereas targeted or immunotherapy in 9 . None of these associated therapies, except chemotherapy in two records, did significantly modify outcomes. Disease-free interval before the redo procedure was the prevailing prognostic factor and nearly all papers showed a significant correlation between patients' comorbidities and prognosis. No perioperative mortality was reported, while perioperative major morbidity was overall quite low. Where available, overall survival after the first redo metastasectomy ranged from 10 to 72 months, with a 5 -years survival of approximately $50 \%$. The site of first recurrence after the redo procedure was mainly lung. Despite the data retrievable from literature are heterogeneous and confounding, we can state that redo lung metastasectomy is worthwhile when the lesions are resectable and the perioperative risk is low. At present, there are no "non-surgical" therapeutic options to replace redo pulmonary metastasectomies.
\end{abstract}

Keywords: Pulmonary metastasectomy; redo metastasectomy; target therapy; immune therapy

Submitted Feb 18, 2020. Accepted for publication May 11, 2020.

doi: $10.21037 /$ jtd-19-4064

View this article at: http://dx.doi.org/10.21037/jtd-19-4064

\section{Introduction}

Within the routine practice of a general thoracic surgeon, it is not uncommon to encounter cases of pulmonary metastases. Their incidence is indeed quite high, ranging from $20 \%$ to $45 \%$ in patients who died from extrathoracic malignancies $(1,2)$. After initial anecdotal attempts, the first case of long-term survival following resection of pulmonary metastasis from a renal adenocarcinoma was reported by Barney and Churchill in 1939 (3). The first feasibility study of pulmonary resection for metastases was undertaken 25 years later by Thomford et al. (4). Since then, numerous papers about lung metastasectomy have been published, displaying encouraging results but low level of evidence (5). In this regard, the actual goal of this procedure is somehow debatable (6), and the only randomized controlled trial is 
still running (7). A task force aiming to clarify the value of pulmonary metastasectomy was established by The Society of Thoracic Surgeons (8), but the statement determined by this consensus of experts cannot be presented as guideline, due to weakness in level of evidence (9).

Furthermore, if lack of evidence appears to be a prominent problem in metastasectomy, redo metastasectomy is a true no man's land.

In this respect, only few studies are specifically focused on repeat lung resections for metastases, thus results and effectiveness of redo metastasectomy effectively derive from a relatively limited number of patients within larger studies addressing the first pulmonary metastasectomy. Nonetheless, redo pulmonary resection is actually frequently performed. Data from a large review of 18 studies reporting on pulmonary metastasectomy for sarcoma in a total of 1,357 cases showed that $43 \%(n=580)$ of the patients underwent redo pulmonary metastasectomy (10). The principal investigator of this review (VA) has over 25 years of experience in redo pulmonary metastasectomy and in 2015 he reported on 113 patients who had undergone at least one redo pulmonary metastasectomy, 54 of them had had two, 31 three, 8 four and 3 up to five repeated operations (11), respectively.

In this current review we summarized most of the studies on redo pulmonary metastasectomy-for different types of malignancies. We also investigated the possible role of molecular subtypes of cancers and we analyzed the results of surgery in association with chemotherapy, immunotherapy or targeted therapy. Hence, we examined the surgical approach to frail patients, who represent a substantial percentage of patients undergoing repeat metastasectomy. Eventually, we analyzed the long-term survival results and tried to outline the current evidences for redo metastasectomy.

\section{Redo pulmonary metastasectomy in specific settings}

A total of 120 studies were included for the final evaluation, and the entire sample size consisted of 3,015 patients. We analyzed these amounts of studies into different sections: colorectal, sarcomatous, other and not focused on a specific histotype. Some of the publications dealing with metastases from colorectal cancer are mostly focused on colon cancer (12-24), others mostly on rectal cancer (25-38) and in the remaining the primary lesion location was unknown (28,33,39-53). Publications focused on sarcomatous metastases gather studies mostly emphasizing hard tissue sarcomas (54-68), others mostly soft tissue sarcomas (69-76) and the residual mostly other sarcomas (77-89). The remaining studies mentioned lung metastases from primary tumors other than colorectal cancers and sarcomas (90-109) or did not focus on a specific histotype (40,110-130). The process of selecting the studies is shown in the PRISMA flow chart (Figure 1). In 79 papers, male was the prevalent gender of patients. Mean age at the time of the first redo metastasectomy was $55.4 \pm 12.1$ years and mean followup time was $42.2 \pm 22.7$ months. According to the available data, the mean disease-free interval before the first redo operation was $8.4 \pm 6.5$ months. In all studies that mentioned it, there was no postoperative mortality. The data about major peri-operative morbidity of the redo procedure was often missing but, when reported, it was negligible in most of studies. Only in one case (19), peri-operative morbidity was two-fold greater than at the time of the first pulmonary metastasectomy.

Some of the papers focused on a specific histological type of cancers while others featured mixed histologies grouped together. For the purposes of this review, we preferred to present the data dividing the studies in groups according to the histology types. The groups we established were the following: colorectal carcinomas $(n=42)$, sarcomas $(n=36)$, other cancers $(n=20)$, all histologies together $(n=22)$. Total number of patients for each subgroup involved in the records are summarized in Table 1. The studies collected in our review cover a time spawn of nearly 30 years (Figure 2) and come from different research groups spread all over the world (Figure 3).

\section{Reports focused on colorectal cancer}

Pulmonary metastases from colorectal cancer represent the most common instance in which redo metastasectomy is performed, and this is valid also for our review. It has also been recently documented that their percentage has constantly increased from less than $15 \%$ in the 1960 's to well over $20 \%$ in the 2000s (131).

In this review, redo pulmonary metastasectomy in patients with primary colorectal cancer was performed in 42 out of the 120 selected studies. The majority of records reported a higher frequency of diagnosis for males under the age of 65 . When reported, there was no difference in regard to the location of the primary tumor in the colon (most frequent in 13 studies) or in the rectum (more frequent in 14 studies). Repeat lung resections were more likely to 


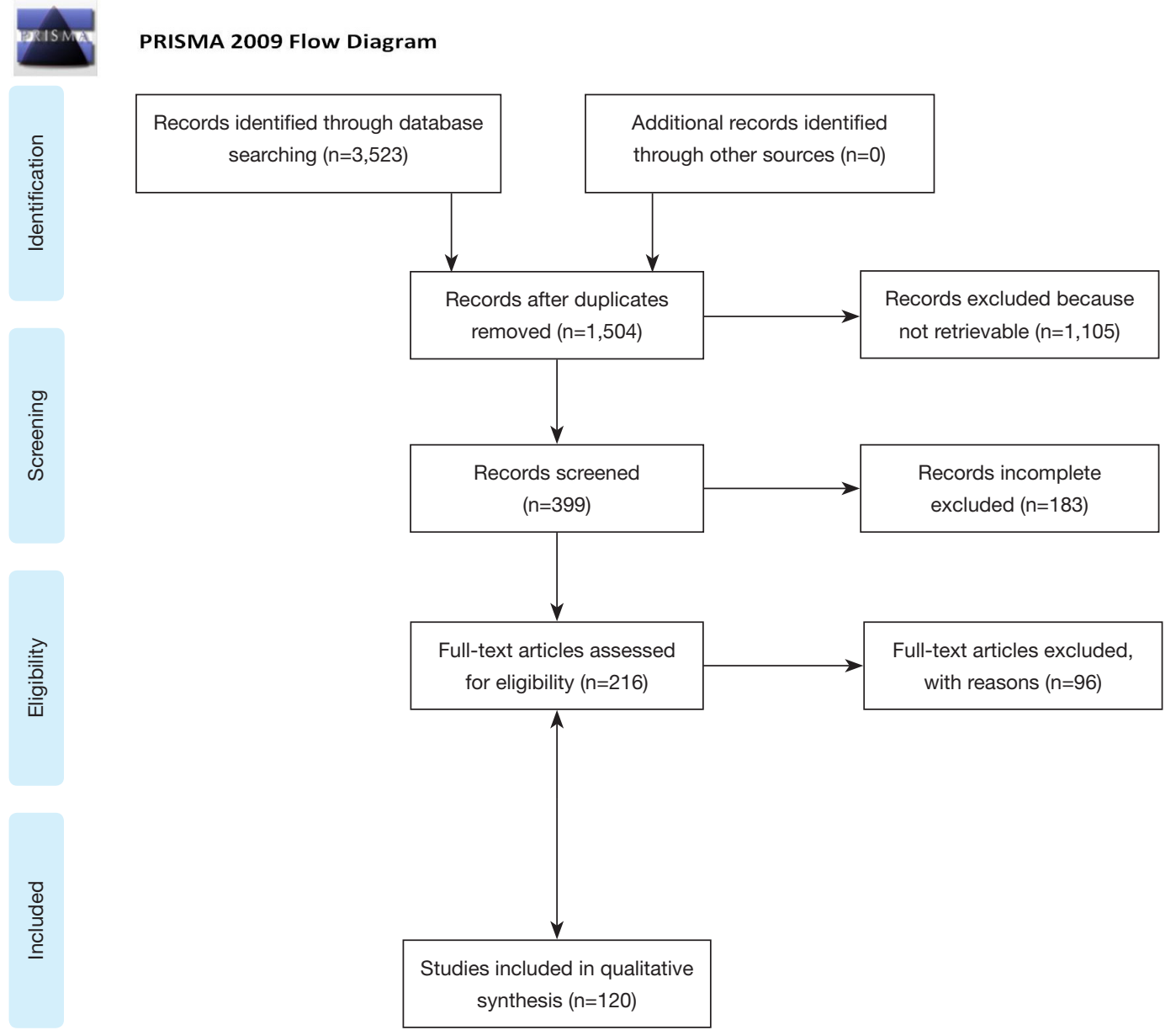

Figure 1 PRISMA algorithm for record inclusion.

Table 1 Number of records and subjects at the different redo included in the review

\begin{tabular}{|c|c|c|c|c|c|c|}
\hline Primitive tumor & Records (n) & First Redo (n) & Second (n) & Third (n) & Fourth (n) & Fifth (n) \\
\hline Other & 20 & 127 & 1 & 1 & - & - \\
\hline All histotypes & 22 & 1,421 & 288 & 110 & 11 & 1 \\
\hline
\end{tabular}

${ }^{\star}$ Repetitions cannot be excluded.

be performed in patients with colorectal cancer at advanced stages (III or IV TNM stage and Duke C or D), as stated in all papers $(n=20)$ where this data was available.

Only 11 records reported on the preferred surgical approach, which was videothoracoscopic surgery (VATS) in 5 studies and thoracotomy in 6. Subanatomic lung resections were more often performed in 14 studies and anatomical resections in 4 , with the other 14 publications not mentioning the extent of resection.

There was no postoperative deaths after the first redo metastasectomy in all records, while major morbidity was hardly mentioned. Only one study reported major 


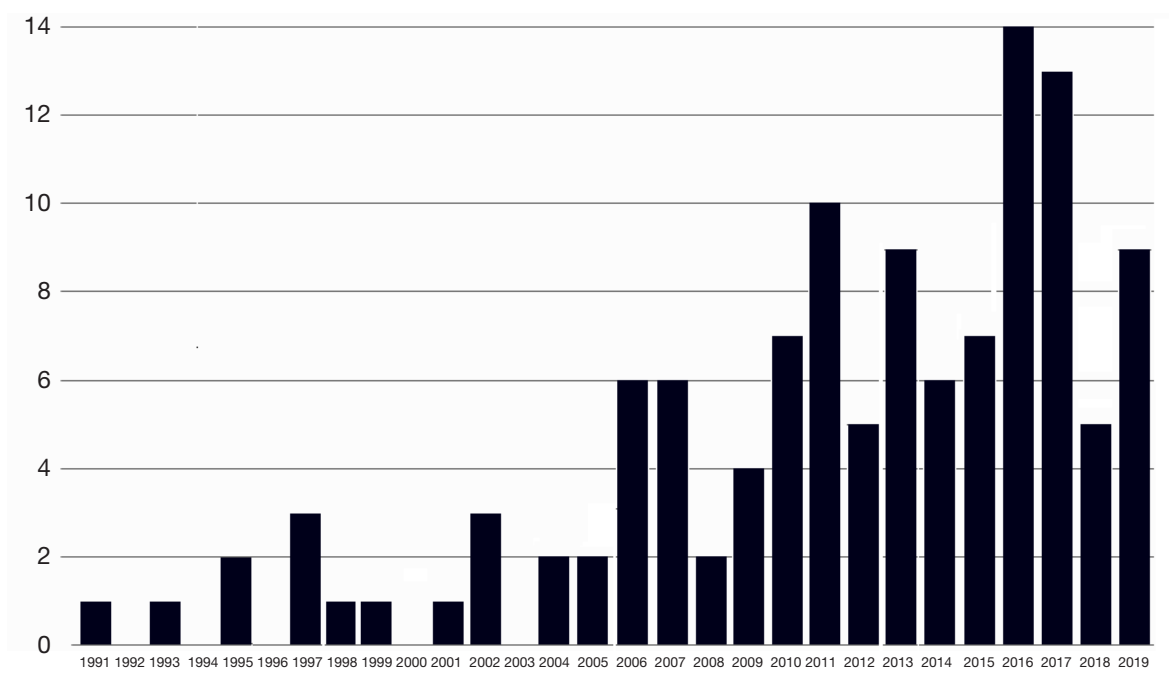

Figure 2 Temporal frequency of the published records about redo per year.

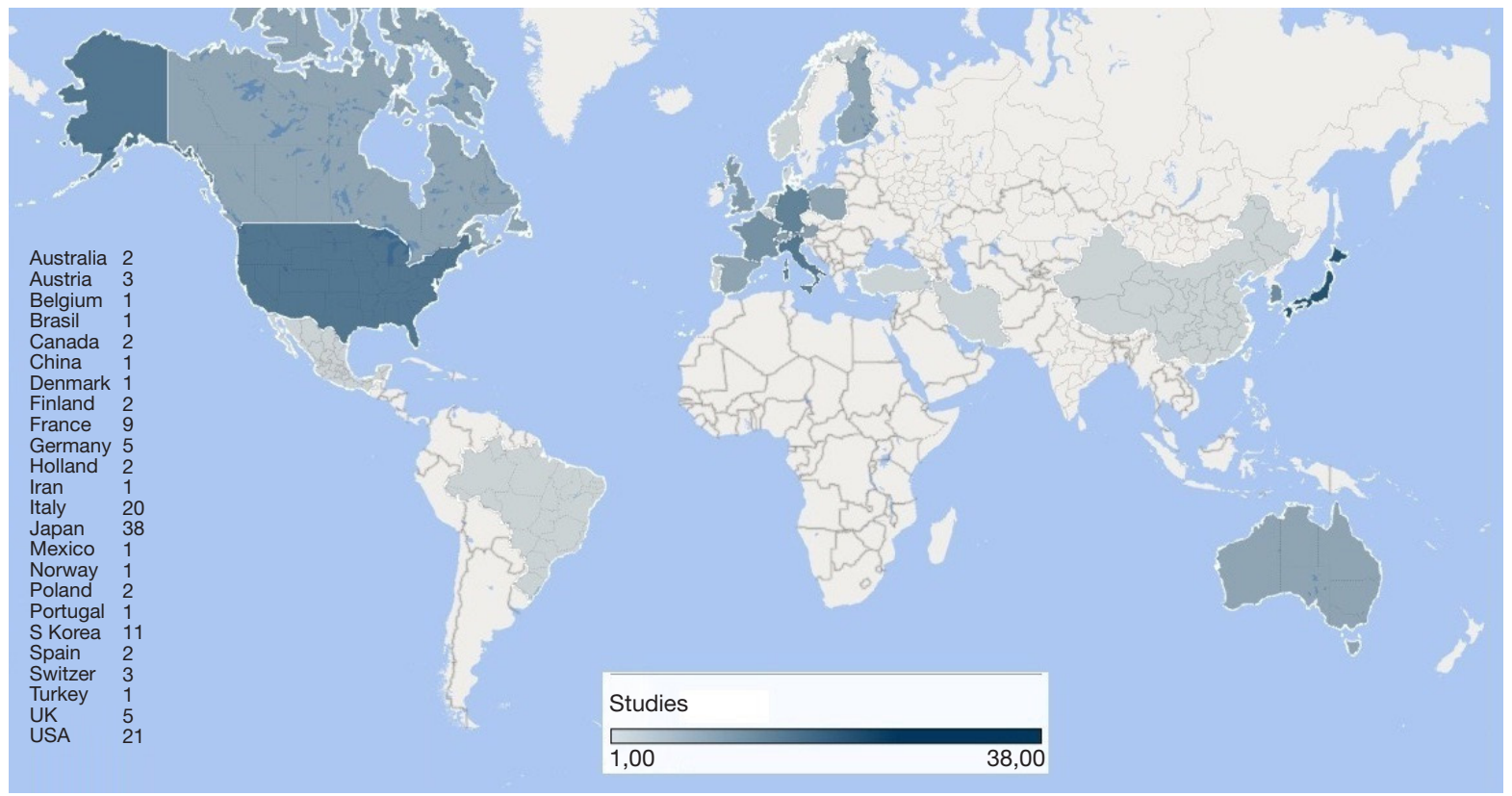

Figure 3 Geographic frequency of the records reporting redo pulmonary metastasectomy.

complications after 21 redo procedures including atrial fibrillation $(n=3)$, prolonged air leak $(n=2)$, bleeding requiring transfusions $(\mathrm{n}=1)$ and bleeding requiring reoperation ( $\mathrm{n}=1)(19)$.

In the setting of redo metastasectomies, it is not easy to distinguish between neoadjuvant and adjuvant treatments. Chemotherapy given at some stage was mentioned in 23 publications. Among them, neoadjuvant chemotherapy was reported in 6 records and adjuvant chemotherapy in 16 .
In 4 studies, both neoadjuvant and adjuvant chemotherapy were administered. Only 6 papers stated which drugs and protocols were used, and among them targeted therapy was utilized in $4(22,30,44,51)$. When statistical analysis was performed (2 reports), biological chemotherapy regimens did not result to be independent statistically significant prognostic indicators of overall survival $(22,51)$. In Figure 4, we summarize the prognostic factors influencing overall survival at multivariate analysis. 


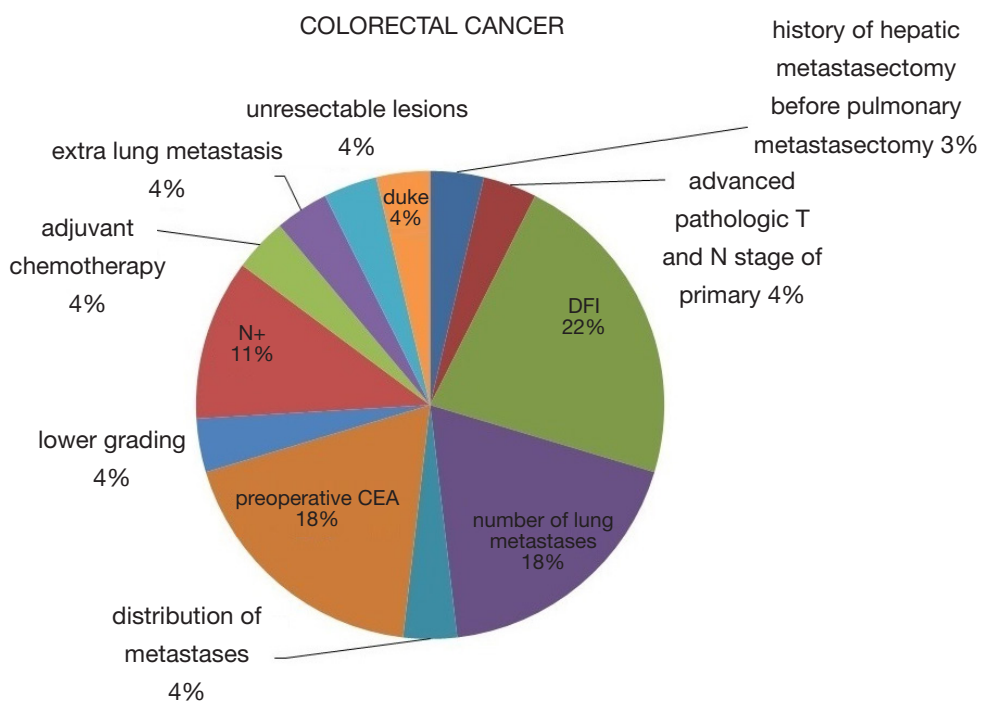

Figure 4 Frequency of the prognostic factors on overall survival selected by multivariate analysis at the time of the first redo pulmonary metastasectomy from colorectal cancer (n. records $=42$ ).

\section{Reports focused on sarcoma}

Redo metastasectomy in patients with sarcoma was documented in 36 out of the 120 records. Of these records, 15 were focused mostly on hard tissue sarcomas (54-68), 8 were focused mostly on soft tissue sarcomas (69-76) and 13 mostly on other sarcomas (77-89). Prevalence of males was exhibited in 20 of the studies. Because of the nature of the disease, the population of patients treated with redo metastasectomy for sarcomas displayed a significant younger age compared to other histotypes. In 5 papers, patients' population consisted mostly of children, with a median age of 18 years-old, whereas in another 29 the population featured young adults aged between 18 and 65 .

The surgical approach of choice for the first redo pulmonary metastasectomy was thoracotomy in 12 records, and subanatomic lung resections were preponderant in 19 studies. Also in redo metastasectomy for sarcomas, no post-operative mortality was observed and data about post-operative morbidity were scant. Two studies clearly stated that the redo procedure did not imply an increased morbidity $(78,79)$.

Administration of chemotherapy was reported in 14 papers. In 3 of them $(56,79,82)$, neoadjuvant treatment was accomplished, while in the other 11 adjuvant treatment after the first metastasectomy was chosen $(56,57,59,66,71,73,79,81,82,84,88)$. The protocols utilized were stated in 7 publications $(56-60,79,84)$, none of them had targeted therapy nor immunotherapy among the chemotherapeutic agents. The prognostic factors at multivariate analysis influencing overall survival are shown in Figure 5.

\section{Reports focused on tumors other than colorectal and sarcoma}

Twenty papers in total dealt with lung metastases from primary tumors other than colorectal cancers and sarcomas (90-109). In view of the small number of studies for each different primary, we deemed more appropriate to present them comprehensively as an "other tumors" group. Out of an overall population of 1,046 patients undergoing lung metastasectomies, 186 patients underwent at least one redo metastasectomy, 13 a second redo and one patient a third redo. Male was again the predominant gender, as displayed by 13 studies. Median age was between 18 and 65 in 2 publications, while only in 2 it was over 65 .

Surgical approach (VATS or thoracotomy) was rarely mentioned, while in 13 records it was reported that the performed resections were mostly subanatomic (90,91,93-97,100,102,104-106,109). The use of chemotherapy was generically reported in 13 records, but neoadjuvant treatment was clearly mentioned in 3 studies $(93,95,107)$ and adjuvant therapy in $6(91,93,95,96,98,108)$, respectively. 


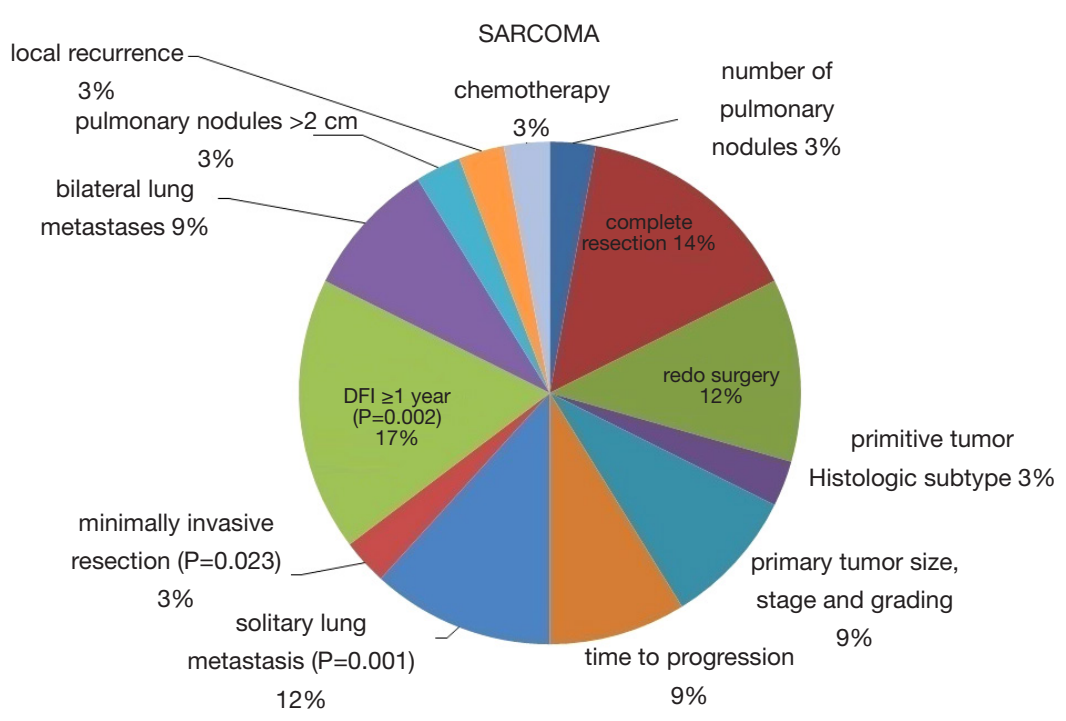

Figure 5 Frequency of the prognostic factors on overall survival selected by multivariate analysis at the time of the first redo pulmonary metastasectomy from sarcoma (n. records $=36)$.

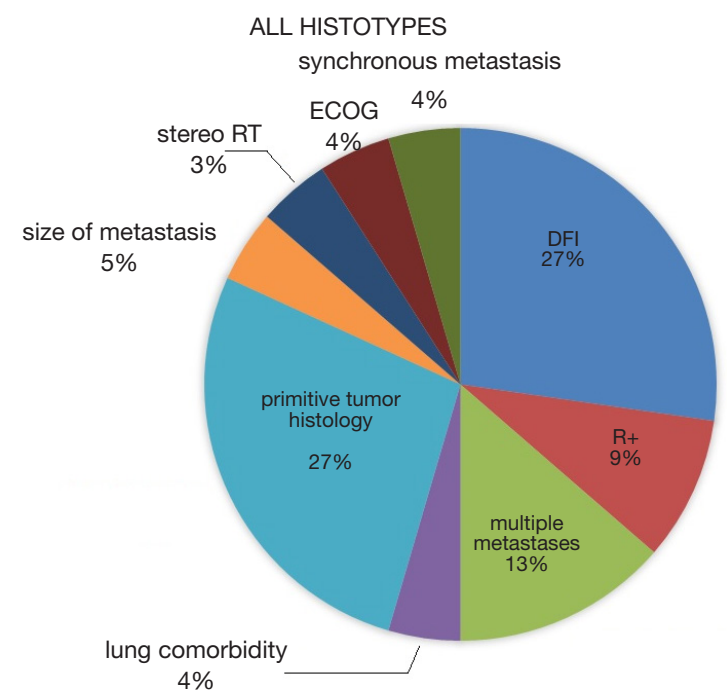

Figure 6 Frequency of the prognostic factors on overall survival selected by multivariate analysis at the time of the first redo pulmonary metastasectomy from all histotypes (n. records $=22$ ).

\section{Reports not focused on a specific bistotype}

Among the 120 papers reviewed, 22 of them did not focus on a specific histotype, but rather dealt with various types of primary cancers (40,110-130). These records incorporate a total of 6,072 patients, 1,332 of them underwent at least one redo, 318 underwent two, 114 underwent three, 22 underwent four and 3 underwent five redo metastasectomies, respectively.
In 20 records male was the prevalent gender among operated patients were prevalent. The median age was $<18$ years old in 4 records, between 18 and 65 in 16 and above $>65$ in one, as a single study did not report it. Interestingly, in the majority of papers, thoracotomy was the most used surgical approach for redo metastasectomies, and subanatomic resection was the preferred procedure. Data about postoperative mortality are generally missing 
but, whenever available, they report no mortality. According to 12 studies, chemotherapy after diagnosis of the primary tumor was utilized at some stage, as neoadjuvant treatment before the redo metastasectomy in 4 papers and as adjuvant therapy following redo resection in $5(40,111,126,127,130)$. The prognostic indicators of overall survival at multivariate analysis for this group are summarized in Figure 6.

\section{Redo metastasectomy associated with non-surgical therapies}

Overall, data about chemotherapy were available in half of the records, although only 26 of them reported the drugs or protocols used. These data are challenging to interpret, as it is not always clear whether the treatments administered are adjuvant or neoadjuvant. In 10 studies, chemotherapy was a predictor of longer overall survival at univariate analysis, and in 2 of them chemotherapy proved to be an independent predictor also at multivariate analysis $(50,56)$. Nevertheless, we also found that chemotherapy was a negative prognostic factor in 2 papers reporting metastasectomies for sarcoma $(74,89)$, probably due to the more aggressive nature of the cancers.

Targeted therapy or immunotherapy were used as singletherapy or in combination with traditional cytotoxic drugs in 9 studies $(22,30,44,51,91,102,104,109,129), 4$ of which focused on colorectal cancers $(22,30,44,51)$. A statistically significant improved overall survival in patients undergoing redo metastasectomy for colorectal cancer who had adjuvant biological therapy was found in only one case (51). In another study instead (22), the use of adjuvant cytotoxic + targeted therapy did not affect disease recurrence after the first pulmonary metastasectomy, whereas the distribution of the metastases (unilateral vs. bilateral) and the stage of the primary cancer were statistically significant factors. In the other studies focused on different primary tumors, the use of targeted or immunotherapy, either within adjuvant or neoadjuvant setting, proved to be a significant predictor of a better outcome.

The potential role of molecular markers in tailoring surgical strategies is becoming of great interest (132). At present, there is some evidence that molecular characterization of the recurrent lesions should drive the surgeon in choosing between a curative-intent or a palliative-intent approach (133). Renaud et al. investigated differences in terms of outcomes after lung metastasectomy for colorectal cancers with different mutational profile (45). The best outcome was observed in patients with tumors expressing protein K-rat sarcoma (KRAS) wild type, although long term survival was reported also when mutant KRAS was present. Conversely, patients presenting mutant B-RAS subfamily (BRAF) had an overall survival 3.5 times shorter than patients with mutant KRAS. Nonetheless, mutant BRAF was more often associated with presence of multiple metastatic lesions and higher nodal involvement, this may somehow explain the aforementioned results. In the studies included in our review, the molecular subtype did not appear to significantly impact the outcomes of repeat pulmonary resections.

Targeted therapy aims at inhibiting cell growth/ spread by specifically targeting growth factors, signaling molecules, cell-cycle proteins, modulators of apoptosis and angiogenesis and other molecules involved in cancer pathogenesis. These treatments have improved the outcomes of several malignancies, such has breast and colorectal cancer (134). Metastases are known to have an increased genetic instability. This may lead to rapid growth of intralesional and interlesional heterogeneity, enabling more frequent occurrences of novel genetic variants. The new cells expressing a modified genotype can thus be resistant to therapy, and this escape mechanics leads to a selective advantage with reemergence of metastatic disease (135). Biological heterogeneity can therefore limit the results of targeted therapy. In several tumors, such as colorectal cancer, drug resistance to immunotherapy and partially to targeted therapy remains a major drawback (136). In a recent review, Cheung et al. depicts an ideal scenario where induction or definitive chemotherapy are supported by the surgical local control of drug-resistant metastatic foci (6). Despite targeted and biological therapies may play a prominent role in the treatment of metastatic and systemic disease, the best outcomes are achieved with the association of surgery and chemotherapy. From our analysis, it appears evident that, at present, even the use advanced chemotherapeutic agents could not replace the role of redo metastasectomies or other strategies for local control, while a synergic approach remains the gold standard.

Immunotherapy was defined as "the breakthrough of the year" in 2013 (137). This therapy aims at enhancing the immunological response of the host against the cancer cells and its use in clinical practice achieved remarkable results in the treatment of several malignant disorders. It is commonly regarded as generally safe, with no important side-effects, albeit immune-related adverse events leading to endocrinological problems have recently been described (138). The role of anti-tumor vaccines can be of great interest as 
Table 2 Calculated mean survivals from the first redo among the different records

\begin{tabular}{|c|c|c|c|c|c|c|c|}
\hline Study & Histology & Patients (n) & Mean OS (months) & 5-year OS (\%) & $\begin{array}{l}\text { Mean pre DFI } \\
\text { (months) }\end{array}$ & $\begin{array}{l}\text { Mean post DFI } \\
\text { (months) }\end{array}$ & 5-year DFS (\%) \\
\hline Menna et al. & Colorectal & 92 & 30 & - & 61 & - & - \\
\hline Welter et al. & Colorectal & 33 & 72.6 & 53.8 & 16.8 & 15.2 & - \\
\hline Rena et al. & Colorectal & 7 & 42.5 & 50 & 20.3 & - & 55 \\
\hline Mizuguchi et al. & Hepatocellular & 5 & 65 & $67^{*}$ & 6.4 & - & 28 \\
\hline Han et al. & Urothelial & 2 & 10 & - & 10 & 3.5 & 37.5 \\
\hline
\end{tabular}

*at 3 years. OS, overall survival; DFI, disease free interval; DFS, disease free survival.

the availability of good quality cancer specimens may aid the development of vaccines based on tumor cells (139). Only one study investigated the administration of an anti-tumor vaccine as an adjuvant therapy in pulmonary metastases from melanoma (140). Among the anti-tumor vaccines, Canvaxin failed to improve outcomes in a phase three study (141). Results of trials involving granulocytemacrophage colony-stimulating factor are equivocal, albeit showing some promising features in the adjuvant treatment of melanoma (142).

\section{Redo metastasectomy in frail patients}

In the setting of repeat metastasectomies, patients' frailty is often a concern that could potentially have an impact on surgical strategy. Nevertheless, in this review frailty did not appear to be factor affecting surgical or therapeutic management. Elderly patients are commonly thought to be more prone to surgical complications and pharmacological side effects. Moreover, frail patients with cancer more often experience chemotherapy toxicity, especially when combination therapies are administered (143). Kim et al. in 2015 (144) reported that elderly patients with locally advanced or metastatic colorectal cancer are more often under-staged and under-treated. To a certain extent, this is also caused by the lack of guidelines and clinical trials aiming at improving treatments' effectiveness while reducing side effects. Certainly, a more specific and agreed definition of "frailty" would be helpful for a more accurate risk assessment and to improve therapeutic strategies. In 2013, an expert consensus defined frailty as: "a medical syndrome with multiple causes and contributors that is characterized by diminished strength, endurance, and reduced physiologic function that increases an individual's vulnerability for developing increased dependency and/or death" (145).

The non-age adjusted version of the Charlson's Comorbidity Index was used in several of the papers selected for this review, and in most of them we did notice a relevant correlation between its score and patients' prognosis (146).

At Thoracic Surgery Unit of Tor Vergata University, a sizeable cohort of frail patients underwent redo pulmonary metastasectomy under non-intubated anesthesia with encouraging results (147). In this setting, nonintubated anesthesia proved effective in reducing systemic inflammatory stress without affecting immunological response (148), as in the non-intubated patients there was reduction of natural killer lymphocytes and less production of interleukin 6. These events could explain the lower incidence of postsurgical infections and the lower morbidity rate reported in the non-intubated group. However, there was not a positive effect on long-term survival, since both disease-free survival and overall survival after surgery were comparable to those of patients operated under general anesthesia (49). Nevertheless, the non-intubated patients experienced a longer-yet not statistically significantdisease-free survival. The small sample size makes this study of limited scientific value, still this non-significant trend shown could be explained by the occurrence of a more active cellular-mediate response, which has been previously demonstrated to be less reduced after non-intubated operations (149).

\section{Analysis of survival}

The analysis of survivals was available in all the examined papers, although given the different starting points, in 
some cases this was incomplete or confounding. We therefore decided to present only those studies with clear and complete data of survivals and outcomes, which are summarized in Table 2. Predictably, more comprehensive data were found for overall survival, which we found ranging from 10 to 72 months with a 5 -year survival rate of approximately $50 \%$. This, which appears like a remarkably good result, must be carefully interpreted. Interestingly, the disease-free interval after redo metastasectomy was quite long in one of the largest series (26) providing, according to us, more evidence to support this procedure.

The most common site of recurrence after redo pulmonary metastasectomy remains the lung, and only three papers document non-pulmonary recurrence after the redo resections $(11,26,41)$. This observation reinforces a common concept about the effectiveness of redo operations for a disease that tends to be confined in the lungs.

Our analysis showed that in general, disease-free interval before the redo metastasectomy, despite different temporal cut-offs used, was the most frequently reported factor affecting overall survival. For colorectal cancer, carcinoembryonic antigen (CEA) preoperative value, mediastinal lymph nodal status and number of metastases were the also frequent prognostic indicators (Figure 4), whereas many more other variables affected prognosis in metastases from sarcomas (Figure 5).

\section{Selection effect}

In 2015, the Tor Vergata Group observed that patients undergoing more than one pulmonary metastasectomy displayed a longer survival compared to those who underwent a single resection (11). This large retrospective study showed that $65 \%$ of patients undergoing repeated metastasectomies were alive after 5 years, compared to the $42 \%$ who underwent only one metastasectomy. This finding was confirmed by other authors who investigated patients with other types of tumors (10). Three or more redo pulmonary metastasectomies favored prolonged survival in patients with (150) and successful resection of recurrent metastatic lesions accomplished a favorable survival despite the number of operations $(58,61)$.

This unexpected behavior seems to be an evident and unexplainable oncological paradox. How can a recurrent tumor entail longer survival? Could the chance of performing repeated resections create somehow more favorable conditions for survival in these patients? Two prominent and experienced investigators were invited to review and interpret these results. The analysis was published in the Journal of Thoracic and Cardiovascular Surgery with the title "Survival is higher after repeat lung metastasectomy than after a first metastasectomy: too good to be true?" (151).

In first instance, this comparison judged was inappropriate, because the two treatment strategies were not randomly assigned. These patients were not indeed allocated to 2 established subgroups of either single metastasectomy or repeated metastasectomies.

The selection of patients for any metastasectomy was based on clinical evaluation at the time of surgery, which still represents a valid influencing factor. The 2 cohort of patients presented rather different chances of long-term survival, as surgical candidates for redo metastasectomies had more likely a better fitness status and presented with slower-growing and more resectable disease. Conversely, patients that were considered inoperable for recurrent metastases, were surely more frail and/or presented a more aggressive cancer. Thus, the difference in survival may well be caused by the "a priori" different survival between groups, with metastasectomies only performed in patients destined to a longer survival.

The importance of the denominator must also be taken into account. The number of suitable candidates for a second, third and so on metastasectomy is significantly lower than the number of patients who can tolerate only one resection. This leads to inevitable bias in calculating all percentages, as well as in the use of the Kaplan-Meier method of analysis.

Nonetheless, lung metastases are rarely a cause of death. It is therefore rather unlikely that the initial flat portion of the survival curve after pulmonary metastasectomy is a direct result of the surgical procedure. More realistically, this results from the selection of patients with higher chances of postoperative survival (152).

Ultimately, this active selection of fit surgical candidates with slow growing disease for redo lung metastasectomy is enhanced by its own repetition (153), causing the differences in survival to become progressively more significant as the time goes by.

Conversely, after the first redo operations, both diseasefree interval and overall survival decreases as the number of operations increases (11). This behavior appears more understandable, and could be caused by the denominator effect and also by the occurrence of more aggressive molecular subtypes of metastatic cells. 


\section{Survival effect}

Does redo metastasectomy prolong survival? The benefit of an aggressive surgical treatment for patients with recurrent pulmonary metastases has not been unequivocally proven yet $(5,6)$. Nevertheless, according to our review, neither targeted therapy, immunotherapy and even molecular subtype strategies have significantly modified the outcomes of repeat lung resections. In addition, none of these therapies have shown convincing results when used alone.

On the other hand, a large bulk of evidence supports the role of redo metastasectomy when performed according to the correct indications. The majority of the recurrent metastases considered to be surgically resectable are usually slow-growing malignancies (151), their response to cytotoxic therapies is therefore poor. It is our experience that the disease-free interval after the first redo lung metastasectomy is usually quite long (26). Furthermore, recurrences after repeat resection tend to remain confined in the lungs, as the chance of distant relapses is rather low. In this setting, local-control strategy like surgery seems to be justifiable.

Slow-growing single or few metastases represent the correct indication for repeat lung resections. Conversely, the presence of multiple and/or bilateral metastases contraindicates repeated procedures, especially if they have arisen after the first redo operations. This scenario is likely to derive from a more selective growth of a rather aggressive malignant cluster of cells. Nonetheless, in the rare instance of a life-threatening location of recurrent metastatic lesions, it is reasonable to accomplish resection (9).

Early diagnosis of recurrence is of paramount importance for long term prognosis. Detecting lung metastases is quite easy nowadays with the use of computed tomography, and other methods like positron emission tomography and radiomics techniques are excellent valid aids (154).

Operative mortality for redo operations is negligible and morbidity is generally quite low, also in frail patients. The following criteria remaining pivotal to accomplish an effecting redo lung metastasectomy: controlled or controllable extrathoracic disease; adequate cardiopulmonary reserve; technically feasibility to resect all detectable metastases, preferring parenchyma-sparing procedures.

A proficient thoracic surgeon should have sufficient experience with several different surgical approaches, both open and minimally-invasive, in order to tailor the operation for maximal effectiveness and minimal surgical trauma.
In 1999 our mentor Professor Mineo developed a new transxiphoid surgical technique, that combines the advantages of minimally-invasive access with the possibility of manually palpating both lungs to detect presence of nodules (155). The transxiphoid approach may be a good alternative to large thoracotomies, especially in the setting of multiple redo operations.

Finally, the evolution towards non-intubated surgical procedures in several, expanded the indications of surgery to the most frail patients with resectable pulmonary metastasis, avoiding the side-effects of general anesthesia.

\section{Summary of evidence}

Data retrieved from available literature provides interesting results for both current evidence and implications for future research.

First of all, the lack of guidelines for redo pulmonary metastasectomy has been underlined, caused by the absence of clear evidence on the effectiveness of lung metastasectomy.

In second place, the review has demonstrated that redo metastasectomy does not carry a significant increment of perioperative mortality or morbidity.

Thirdly, patients undergoing redo metastasectomies have longer survival when compared to those undergoing only one pulmonary metastasectomy, but this may well be the result of an active selection of patients with higher chances of survival.

Fourth, whenever the lesion is resectable and the surgical risk is low, redo lung metastasectomy is worthwhile. At present, even the advanced antiblastic therapy and chemotherapeutic agents could not replace redo metastasectomies and local-control strategies, whereas a synergic strategy remains the gold standard. The outcome mainly depends on the biology of the tumor, hence the predictable importance of targeted therapy.

Last but not least, data retrievable from the literature are heterogeneous and sometimes confounding. Established guidelines deriving from multicenter prospective efforts are certainly desirable.

\section{Conclusions}

In conclusion, lung metastases can be resected with low risk and are a tempting target. While their removal may be a rewarding surgical strategy, actual proof of a true survival benefit is still lacking. The idea that longer survival is an 
effect of repeated operations cannot be reliably stated based on observational data. Nevertheless, none of the alternative therapies have shown results comparable to surgery. At present, non-surgical therapies cannot replace redo metastasectomies and local-control strategies, while synergic therapies that include redo metastasectomy are considered the current gold standard.

We thank the editors for having entrusted us with such a challenging, yet fascinating topic.

\section{Acknowledgments}

Funding: None.

\section{Footnote}

Provenance and Peer Review: This article was commissioned by the Guest Editor (Khosro Hekmat) for the series "Pulmonary Metastases" published in Fournal of Thoracic Disease. The article has undergone external peer review.

Conflicts of Interest: The authors have completed the ICMJE uniform disclosure form (available at http:// dx.doi.org/10.21037/jtd-19-4064). The series "Pulmonary Metastases" was commissioned by the editorial office without any funding or sponsorship. The authors have no other conflicts of interest to declare.

Ethical Statement: The authors are accountable for all aspects of the work in ensuring that questions related to the accuracy or integrity of any part of the work are appropriately investigated and resolved.

Open Access Statement: This is an Open Access article distributed in accordance with the Creative Commons Attribution-NonCommercial-NoDerivs 4.0 International License (CC BY-NC-ND 4.0), which permits the noncommercial replication and distribution of the article with the strict proviso that no changes or edits are made and the original work is properly cited (including links to both the formal publication through the relevant DOI and the license). See: https://creativecommons.org/licenses/by-nc-nd/4.0/.

\section{References}

1. Snyder BJ, Pugatch RD. Imaging characteristics of metastatic disease to the chest. Chest Surg Clin N Am 1998;8:29-48.
2. Seo JB, Im JG, Goo JM, et al. Atypical pulmonary metastases: spectrum of radiologic findings. Radiographics 2001;21:403-17.

3. Barney JD, Churchill EJ. Adenocarcinoma of the kidney with metastasis to the lung: cured by nephrectomy and lobectomy. J Urol 1939;42:269-76.

4. Thomford NR, Woolner LB, Clagett OT. The surgical treatment of metastatic tumors in the lungs. J Thorac Cardiovasc Surg 1965;49:357-63.

5. Aberg T, Malmberg KA, Nilsson B, et al. The effect of metastasectomy: fact or fiction? Ann Thorac Surg 1980;30:378-84.

6. Cheung FP, Alam NZ, Wright GM. The past, present and future of pulmonary metastasectomy: a review article. Ann Thorac Cardiovasc Surg 2019;25:129-41.

7. Treasure T, Fallowfield L, Lees B, et al. Pulmonary metastasectomy in colorectal cancer: the PulMiCC trial. Thorax 2012;67:185-7.

8. Internullo E, Cassivi SD, Van Raemdonck DD, et al. ESTS Pulmonary Metastasectomy Working Group. Pulmonary metastasectomy: a survey of current practice amongst members of the European Society of Thoracic Surgeons. J Thorac Oncol 2008;3:1257-66.

9. Handy JR, Bremner RM, Todd SC, et al. Expert consensus document on pulmonary metastasectomy. Ann Thorac Surg 2019;107:631-49.

10. Treasure T, Fiorentino F, Scarci M, et al. Pulmonary metastasectomy for sarcoma: a systematic review of reported outcomes in the context of Thames Cancer Registry data. BMJ Open 2012;2:e001736.

11. Mineo TC, Ambrogi V, Tacconi F, et al. Multi-reoperations for lung metastases. Future Oncol 2015;11:37-41.

12. Sakamoto T, Tsubota N, Iwanaga K, et al. Pulmonary resection for metastases from colorectal cancer. Chest 2001;119:1069-72.

13. Rena O, Casadio C, Viano F, et al. Pulmonary resection for metastases from colorectal cancer: factors influencing prognosis. Twenty-year experience. Eur J Cardiothorac Surg 2002;21:906-12.

14. Inoue $M$, Ohta $M$, Iuchi $K$, et al. Benefits of surgery for patients with pulmonary metastases from colorectal carcinoma. Ann Thorac Surg 2004;78:238-44.

15. Koga R, Yamamoto J, Saiura A, et al. Surgical resection of pulmonary metastases from colorectal cancer: Four favourable prognostic factors. Jpn J Clin Oncol 2006;36:643-8.

16. Morise Z, Sugioka A, Fujita J, et al. Does repeated surgery improve the prognosis of colorectal liver metastases? J 
Gastrointest Surg 2006;10:6-11.

17. Shah SA, Haddad R, Al-Sukhni W, et al. Surgical resection of hepatic and pulmonary metastases from colorectal carcinoma. J Am Coll Surg 2006;202:468-75.

18. Takahashi S, Nagai K, Saito N, et al. Multiple resections for hepatic and pulmonary metastases of colorectal carcinoma. Jpn J Clin Oncol 2007;37:186-92.

19. Borasio P, Gisabella M, Billé A, et al. Role of surgical resection in colorectal lung metastases: analysis of 137 patients. Int J Colorectal Dis 2011;26:183-90.

20. Suemitsu R, Takeo S, Kusumoto E, et al. Results of a pulmonary metastasectomy in patients with colorectal cancer. Surg Today 2011;41:54-9.

21. Brandi G, Corbelli J, de Rosa F, et al. Second surgery or chemotherapy for relapse after radical resection of colorectal cancer metastases. Langenbecks Arch Surg 2012;397:1069-77.

22. Ihn $\mathrm{MH}$, Kim DW, Cho S, et al. Curative resection for metachronous pulmonary metastases from colorectal cancer: analysis of survival rates and prognostic factors. Cancer Res Treat 2017;49:104-15.

23. Yokoyama S, Mitsuoka M, Kinugasa T, et al. Survival after initial lung metastasectomy for metastatic colorectal cancer in the modern chemotherapeutic era. BMC Surg 2017;17:54.

24. Bellier J, De Wolf J, Hebbar M, et al. Repeated resections of hepatic and pulmonary metastases from colorectal cancer provide long-term survival. World J Surg 2018;42:1171-9.

25. Saito Y, Omiya H, Kohno K, et al. Pulmonary metastasectomy for 165 patients with colorectal carcinoma: A prognostic assessment. J Thorac Cardiovasc Surg 2002;124:1007-13.

26. Welter S, Jacobs J, Krbek T, et al. Long-term survival after repeated resection of pulmonary metastases from colorectal cancer. Ann Thorac Surg 2007;84:203-10.

27. Maeda R, Isowa N, Onuma H, et al. Pulmonary resection for metastases from colorectal carcinoma. Interact Cardiovasc Thorac Surg 2009;9:640-4.

28. Chen F, Sakai H, Miyahara R, et al. Repeat resection of pulmonary metastasis is beneficial for patients with colorectal carcinoma. World J Surg 2010;34:2373-8.

29. Park JS, Kim HK, Choi YS, et al. Outcomes after repeated resection for recurrent pulmonary metastases from colorectal cancer. Ann Oncol 2010;21:1285-9.

30. Riquet M, Foucault C, Cazes A, et al. Pulmonary resection for metastases of colorectal adenocarcinoma. Ann Thorac Surg 2010;89:375-80.
31. Bölükbas S, Sponholz S, Kudelin N, et al. Risk factors for lymph node metastases and prognosticators of survival in patients undergoing pulmonary metastasectomy for colorectal cancer. Ann Thorac Surg 2014;97:1926-32.

32. Takahashi W, Nakajima M, Yamamoto N, et al. Carbon ion radiotherapy for oligo-recurrent lung metastases from colorectal cancer: a feasibility study. Radiat Oncol 2014;9:68.

33. Suzuki H, Kiyoshima M, Kitahara M, et al. Long-term outcomes after surgical resection of pulmonary metastases from colorectal cancer. Ann Thorac Surg 2015;99:435-40.

34. Kim S, Kim HK, Cho JH, et al. Prognostic factors after pulmonary metastasectomy of colorectal cancers: influence of liver metastasis. World J Surg Oncol 2016;14:201.

35. Hishida T, Tsuboi M, Okumura T, et al. Does repeated lung resection provide long-term survival for recurrent pulmonary metastases of colorectal cancer? Results of a retrospective Japanese multicenter study. Ann Thorac Surg 2017;103:399-405.

36. Moorcraft SY, Jones T, Walker BA, et al. Molecular profiling of colorectal pulmonary metastases and primary tumours: implications for targeted treatment. Oncotarget 2017;8:64999-5008.

37. Sponholz S, Schirren M, Baldes N, et al. Repeat resection for recurrent pulmonary metastasis of colorectal cancer. Langenbecks Arch Surg 2017;402:77-85.

38. Yang KM, Park IJ, Lee JL, et al. Benefits of repeated resections for liver and lung metastases from colorectal cancer. Asian J Surg 2020;43:102-9.

39. Nakajima J, Murakawa T, Fukami T, et al. Is finger palpation at operation indispensable for pulmonary metastasectomy in colorectal cancer? Ann Thorac Surg 2007;84:1680-4.

40. Ríos A, Galindo PJ, Torres J, et al. Factors causing early relapse after lung metastasis surgery. Eur J Cancer Care (Engl) 2007;16:26-32.

41. Joosten J, Bertholet J, Keemers-Gels M, et al. Pulmonary resection of colorectal metastases in patients with or without a history of hepatic metastases. Eur J Surg Oncol 2008;34:895-9.

42. Yamato Y, Koike T, Yoshiya K, et al. Factors influencing long-term survival and surgical indications for pulmonary metastasectomy for metastases from colorectal cancer. Thorac Cancer 2011;2:95-100.

43. Chao YK, Chang HC, Wu YC, et al. Management of lung metastases from colorectal cancer: video-assisted thoracoscopic surgery versus thoracotomy--a case-matched study. Thorac Cardiovasc Surg 2012;60:398-404. 
44. Tsukamoto S, Kinugasa Y, Yamaguchi T, et al. Survival after resection of liver and lung colorectal metastases in the era of modern multidisciplinary therapy. Int J Colorectal Dis 2014;29:81-7.

45. Renaud S, Romain B, Falcoz PE, et al. KRAS and BRAF mutations are prognostic biomarkers in patients undergoing lung metastasectomy of colorectal cancer. Br J Cancer 2015;112:720-8.

46. Guerrera F, Mossetti C, Ceccarelli M, et al. Surgery of colorectal cancer lung metastases: analysis of survival, recurrence and re-surgery. J Thorac Dis 2016;8:1764-71.

47. Hachimaru A, Maeda R, Suda T, et al. Repeat pulmonaryresection for recurrent lung metastases from colorectal cancer: an analysis of prognostic factors. Interact Cardiovasc Thorac Surg 2016;22:826-30.

48. Nachira D, Congedo MT, Cassano A, et al. eComment. Iterative metastasectomy for recurrent pulmonary disease from colorectal cancer: a challenging issue. Interact Cardiovasc Thorac Surg 2016;22:830.

49. Ambrogi V, Sellitri F, Perroni G, et al. Uniportal videoassisted thoracic surgery colorectal lung metastasectomy in non-intubated anesthesia. J Thorac Dis 2017;9:254-61.

50. Kanzaki R, Inoue M, Kimura T, et al. Role of pulmonary metastasectomy in colorectal cancer in the era of modern multidisciplinary therapy. Surg Today 2017;47:1111-8.

51. Menna C, Berardi G, Tierno SM, et al. Do repeated operations for recurrent colorectal lung metastases result in improved survival? Ann Thorac Surg 2018;106:421-7.

52. Reijonen P, Kivelä A, Rantonen J, et al. Long-term outcome after sequential liver and lung metastasectomy is comparable to outcome of isolated liver or lung metastasectomy in colorectal carcinoma. Surg Oncol 2019;30:22-6.

53. Matsumoto T, Hasegawa S, Hida K, et al. Role of repeat resection in patients with metastatic colorectal cancer: a multicenter retrospective study. Dis Colon Rectum 2019;62:561-7.

54. Martini N, Huvos AG, Miké V, et al. Multiple Pulmonary resections in the treatment of osteogenic sarcoma. Ann Thorac Surg 1971;12:271-80.

55. Saltzman DA, Snyder CL, Ferrell KL, et al. Aggressive metastasectomy for pulmonic sarcomatous metastases: a follow-up study. Am J Surg 1993;166:543-7.

56. Saeter G, Høie J, Stenwig AE, et al. Systemic relapse of patients with osteogenic sarcoma. Prognostic factors for long term survival. Cancer 1995;75:1084-93.

57. Antunes M, Bernardo J, Salete M, et al. Excision of pulmonary metastases of osteogenic sarcoma of the limbs.
Eur J Cardiothorac Surg 1999;15:592-6.

58. Briccoli A, Rocca M, Salone M, et al. Resection of recurrent pulmonary metastases in patients with osteosarcoma. Cancer 2005;104:1721-5.

59. Dominkus M, Ruggieri P, Bertoni F, et al. Histologically verified lung metastases in benign giant cell tumours -14 cases from a single institution. Int Orthop 2006;30:499504.

60. Harting MT, Blakely ML, Jaffe N, et al. Long-term survival after aggressive resection of pulmonary metastases among children and adolescents with osteosarcoma. J Pediatr Surg 2006;41:194-9.

61. Chen F, Fujinaga T, Sato K, et al. Significance of tumor recurrence before pulmonary metastasis in pulmonary metastasectomy for soft tissue sarcoma. Eur J Surg Oncol 2009;35:660-5.

62. Chen F, Miyahara R, Bando T, et al. Repeat resection of pulmonary metastasis is beneficial for patients with osteosarcoma of the extremities. Interact Cardiovasc Thorac Surg 2009;9:649-53.

63. García Franco CE, Torre W, Tamura A, et al. Longterm results after resection for bone sarcoma pulmonary metastases. Eur J Cardiothorac Surg 2010;37:1205-8.

64. Kim S, Ott HC, Wright CD, et al. Pulmonary resection of metastatic sarcoma: prognostic factors associated with improved outcomes. Ann Thorac Surg 2011;92:1780-6.

65. Daw NC, Chou AJ, Jaffe N, et al. Recurrent osteosarcoma with a single pulmonary metastasis: a multi-institutional review. Br J Cancer 2015;112:278-82.

66. Hamaji M, Chen F, Miyamoto E, et al. Surgical and nonsurgical management of repeat pulmonary metastasis from sarcoma following first pulmonary metastasectomy. Surg Today 2016;46:1296-300.

67. Lim S, Lee S, Rha SY, et al. Cranofacial osteosarcoma: single institutional experience in Korea. Asia Pac J Clin Oncol 2016;12:e149-53.

68. Yamamoto Y, Kanzaki R, Kanou T, et al. Longterm outcomes and prognostic factors of pulmonary metastasectomy for osteosarcoma and soft tissue sarcoma. Int J Clin Oncol 2019;24:863-70.

69. Burt BM, Ocejo S, Mery CM, et al. Repeated and aggressive pulmonary resections for leiomyosarcoma metastases extends survival. Ann Thorac Surg 2011;92:1202-7.

70. Said SM, Sundt TM 3rd, Garces YI, et al. 5-year survival after multiple repeat metastasectomy for pulmonary artery angiosarcoma. Ann Thorac Surg 2011;91:e49-51.

71. Mizuno T, Taniguchi T, Ishikawa Y, et al. Pulmonary 
metastasectomy for osteogenic and soft tissue sarcoma: who really benefits from surgical treatment? Eur J Cardiothorac Surg 2013;43:795-9.

72. Paramanathan A, Wright G. Pulmonary metastasectomy for sarcoma of gynaecologic origin. Heart Lung Circ 2013;22:270-5.

73. Reza J, Sammann A, Jin C, et al. Aggressive and minimally invasive surgery for pulmonary metastasis of sarcoma. $\mathrm{J}$ Thorac Cardiovasc Surg 2014;147:1193-200.

74. Schmid S, Le UT, Zeisel C, et al. Pulmonary metastasectomy in sarcoma-experiences with laser-assisted resection. J Thorac Dis 2018;10:314-20.

75. Wigge S, Heißner K, Steger V, et al. Impact of surgery in patients with metastatic soft tissue sarcoma: a monocentric retrospective analysis. J Surg Oncol 2018;118:167-76.

76. Nevala R, Jäämaa S, Tukiainen E, et al. Long-term results of surgical resection of lung metastases from soft tissue sarcoma: A single center experience. J Surg Oncol 2019;120:168-75.

77. Casson AG, Putnam JB, Natarajan G, et al. Efficacy of pulmonary metastasectomy for recurrent soft tissue sarcoma. J Surg Oncol 1991;47:1-4.

78. Kodama K, Doi O, Higashiyama M, et al. Surgery for multiple lung metastases from alveolar soft-part sarcoma. Surg Today 1997;27:806-11.

79. Pfannschmidt J, Klode J, Muley T, et al. Pulmonary resection for metastatic osteosarcomas: a retrospective analysis of 21 patients. Thorac Cardiovasc Surg 2006;54:120-3.

80. Liebl LS, Elson F, Quaas A, et al. Value of repeat resection for survival in pulmonary metastases from soft tissue sarcoma. Anticancer Res 2007;27:2897-902.

81. Rehders A, Hosch SB, Scheunemann P, et al. Benefit of surgical treatment of lung metastasis in soft tissue sarcoma. Arch Surg 2007;142:70-5.

82. Sardenberg RA, Figueiredo LP, Haddad FJ, et al. Pulmonary metastasectomy from soft tissue sarcomas. Clinics (Sao Paulo) 2010;65:871-6.

83. Tsai J, Mattei P. Median sternotomy for bilateral pulmonary metastasectomy in children. J Pediatr Surg 2012;47:1345-8.

84. Toussi MS, Bagheri R, Dayani M, et al. Pulmonary metastasectomy and repeat metastasectomy for soft-tissue sarcoma. Asian Cardiovasc Thorac Ann 2013;21:437-42.

85. Erginel B, Gun Soysal F, et al. Pulmonary metastasectomy in pediatric patients. World J Surg Oncol 2016;14:27.

86. Lee K, Kang MC, Lee HW, et al. Pulmonary metastasectomy in adult patients with synovial sarcoma: a single-center experience. Korean J Thorac Cardiovasc Surg 2016;49:451-5.

87. Okiror L, Peleki A, Moffat D, et al. Survival following pulmonary metastasectomy for sarcoma. Thorac Cardiovasc Surg 2016;64:146-9.

88. Chudgar NP, Brennan MF, Tan KS, et al. Is repeat pulmonary metastasectomy indicated for soft tissue sarcoma? Ann Thorac Surg 2017;104:1837-45.

89. Chudgar NP, Brennan MF, Munhoz RR, et al. Pulmonary metastasectomy with therapeutic intent for soft-tissue sarcoma. J Thorac Cardiovasc Surg 2017;154:319-330.e1.

90. Nakajima J, Tanaka M, Matsumoto J, et al. Appraisal of surgical treatment for pulmonary metastasis from hepatocellular carcinoma. World J Surg 2005;29:715-8.

91. Andrews S, Robinson L, Cantor A, et al. Survival after surgical resection of isolated pulmonary metastases from malignant melanoma. Cancer Control 2006;13:218-23.

92. Bobbio A, Copelli C, Ampollini L, et al. Lung metastasis resection of adenoid cystic carcinoma of salivary glands. Eur J Cardiothorac Surg 2008;33:790-3.

93. Okubo K, Bando T, Miyahara R, et al. Resection of pulmonary metastasis of non-small cell lung cancer. J Thorac Oncol 2009;4:203-7.

94. Mochizuki T, Okumura S, Ishii G, et al. Surgical resection for oral tongue cancer pulmonary metastases. Interact Cardiovasc Thorac Surg 2010;11:56-9.

95. op den Winkel J, Pfannschmidt J, Muley T, et al. Metastatic adrenocortical carcinoma: results of 56 pulmonary metastasectomies in 24 patients. Ann Thorac Surg 2011;92:1965-70.

96. Kanzaki R, Higashiyama M, Fujiwara A, et al. Long-term results of surgical resection for pulmonary metastasis from renal cell carcinoma: a 25-year single-institution experience. Eur J Cardiothorac Surg 2011;39:167-72.

97. Han WS, Kim K, Park JS. Result of surgical resection for pulmonary metastasis from urothelial carcinoma. Korean J Thorac Cardiovasc Surg 2012;45:242-5.

98. Kycler W, Laski P. Surgical approach to pulmonary metastases from breast cancer. Breast J 2012;18:52-7.

99. Park HW, Hwang S, Ahn CS, et al. Long-term survival outcomes for living donor liver transplant recipients with pathologically nonviable hepatocellular carcinoma. Transplant Proc 2013;45:3032-4.

100. Baier B, Kern A, Kaderali L, et al. Retrospective survival analysis of 237 consecutive patients with multiple pulmonary metastases from advanced renal cell carcinoma exclusively resected by a 1318-nm laser. Interact Cardiovasc Thorac Surg 2015;21:211-7. 
101. Kim T, Ahn JH, You D, et al. Pulmonary metastasectomy could prolong overall survival in select cases of metastatic urinary tract cancer. Clin Genitourin Cancer 2015;13:e297-e304.

102.Mizuguchi S, Nishiyama N, Izumi N, et al. Clinical significance of multiple pulmonary metastasectomy for hepatocellular carcinoma. World J Surg 2016;40:380-7.

103. Abdelnour-Berchtold E, Perentes JY, Ris HB, et al. Survival and local recurrence after video-assisted thoracoscopic lung metastasectomy. World J Surg 2016;40:373-9.

104. Ueno T, Yamashita M, Sawada S, et al. Pulmonary metastasectomy from renal cell carcinoma including 3 cases with sarcomatoid component. Gen Thorac Cardiovasc Surg 2016;64:149-52.

105.Hu Z, Li W, Huang P, et al. Therapeutic significance and indications of pulmonary metastasectomy for hepatocellular carcinoma following liver resection. Int J Surg 2017;48:23-31.

106. Yamada M, Ebata T, Yokoyama Y, et al. Pulmonary metastasis after resection of cholangiocarcinoma: incidence, resectability, and survival. World J Surg 2017;41:1550-7.

107. Tagawa T, Ito K, Fukuzawa K, et al. Surgical resection for pulmonary metastasis from pancreatic and biliary tract cancer. Anticancer Res 2017;37:1413-6.

108. Glenn JA, Else T, Hughes DT, et al. Longitudinal patterns of recurrence in patients with adrenocortical carcinoma. Surgery 2019;165:186-95.

109. Yevich S, Calandri M, Gravel G, et al. Reiterative radiofrequency ablation in the management of pediatric patients with hepatoblastoma metastases to the lung, liver, or bone. Cardiovasc Intervent Radiol 2019;42:41-7.

110.al-Kattan K, Goldstraw P. Completion pneumonectomy: indications and outcome. J Thorac Cardiovasc Surg 1995;110:1125-9.

111.Pastorino U, Buyse M, Friedel G, et al;International Registry of Lung Metastases. Long-term results of lung metastasectomy: prognostic analyses based on 5,206 cases. J Thorac Cardiovasc Surg 1997;113:37-49.

112. Robert JH, Ambrogi V, Mermillod B, et al. Factors influencing long-term survival after lung metastasectomy. Ann Thorac Surg 1997;63:777-84.

113.Kandioler D, Krömer E, Tüchler H, et al. Long-term results after repeated surgical removal of pulmonary metastases. Ann Thorac Surg 1998;65:909-12.

114. Rolle A, Koch R, Alpard SK, et al. Lobe-sparing resection of multiple pulmonary metastases with a new 1318- nm Nd:YAG laser - first 100 patients. Ann Thorac Surg 2002;74:865-9.

115.Jungraithmayr W, Hasse J, Stoelben E. Completion pneumonectomy for lung metastases. Eur J Surg Oncol 2004;30:1113-7.

116. Kondo R, Hamanaka K, Kawakami S, et al. Benefits of video-assisted thoracic surgery for repeated pulmonary metastasectomy. Gen Thorac Cardiovasc Surg 2010;58:516-23.

117. Casiraghi M, De Pas T, Maisonneuve P, et al. A 10-year single-center experience on 708 lung metastasectomies: the evidence of the "international registry of lung metastases". J Thorac Oncol 2011;6:1373-8.

118. Hornbech K, Ravn J, Steinbrüchel DA. Outcome after pulmonary metastasectomy: analysis of 5 years consecutive surgical resections 2002-2006. J Thorac Oncol 2011;6:1733-40.

119. Corona-Cruz JF, Domínguez-Parra LM, Saavedra-Pérez $\mathrm{D}$, et al. Lung metastasectomy: long-term outcomes in an 18-year cohort from a single center. Surg Oncol 2012;21:237-44.

120. Filosso PL, Ruffini E, Sandri A, et al. Efficacy and safety of human fibrinogen-thrombin patch (TachoSil®) in the treatment of postoperative air leakage in patients submitted to redo surgery for lung malignancies: a randomized trial. Efficacy and safety of human fibrinogen-thrombin patch $\left(\right.$ TachoSil $\left.^{\circledR}\right)$ in the treatment of postoperative air leakage in patients submitted to redo surgery for lung malignancies: a randomized trial. Interact Cardiovasc Thorac Surg 2013;16:661-6.

121.Han KN, Kang CH, Park IK, et al. Thoracoscopic resection of solitary lung metastases evaluated by using thin-section chest computed tomography: is thoracoscopic surgery still a valid option? Gen Thorac Cardiovasc Surg 2013;61:565-70.

122.Inoue T, Oh RJ, Shiomi H, et al. Stereotactic body radiotherapy for pulmonary metastases. Prognostic factors and adverse respiratory events. Strahlenther Onkol 2013;189:285-92.

123.Lo Faso F, Solaini L, Lembo R, et al. Thoracoscopic lung metastasectomies: a 10-year, single-center experience. Surg Endosc 2013;27:1938-44.

124.Han KN, Kang CH, Park IK, et al. Thoracoscopic approach to bilateral pulmonary metastasis: is it justified? Interact Cardiovasc Thorac Surg 2014;18:615-20.

125. de Baère T, Aupérin A, Deschamps F, et al. Radiofrequency ablation is a valid treatment option for lung metastases: experience in 566 patients with 1037 metastases. Ann 
Oncol 2015;26:987-91.

126. Shi Y, Geller JI, Ma IT, et al. Relapsed hepatoblastoma confined to the lung is effectively treated with pulmonary metastasectomy. J Pediatr Surg 2016;51:525-9.

127. Franzke K, Natanov R, Zinne N, et al. Pulmonary metastasectomy - A retrospective comparison of surgical outcomes after laser-assisted and conventional resection. Eur J Surg Oncol 2017;43:1357-64.

128. Cheung F, Alam N, Wright G. Pulmonary metastasectomy: analysis of survival and prognostic factors in 243 patients. ANZ J Surg 2018;88:1316-21.

129. Kanzaki R, Kanou T, Ose N, et al. Proposal of a useful surrogate endpoint of the overall survival in patients undergoing pulmonary metastasectomy: the time to local therapy failure. World J Surg 2019;43:2640-6.

130.Londero F, Morelli A, Parise O, et al. Lymphadenectomy during pulmonary metastasectomy: Impact on survival and recurrence. J Surg Oncol 2019;120:768-78.

131. Fiorentino F, Treasure T. A plea for consistency in the reporting of surgical series illustrated with an analysis of 51 follow-up reports of pulmonary metastasectomy in colorectal carcinoma. J Thorac Oncol 2010;5:S192-5.

132. Karagkounis G, Torbenson MS, Daniel HD, et al. Incidence and prognostic impact of KRAS and BRAF mutation in patients undergoing liver surgery for colorectal metastases. Cancer 2013;119:4137-44.

133. Nelson AC, Boone J, Cartwright D, et al. Optimal detection of clinically relevant mutations in colorectal carcinoma: sample pooling overcomes intra-tumoral heterogeneity. Mod Pathol 2018;31:343-9.

134.Lee YT, Tan YJ, Oon CE. Molecular targeted therapy: Treating cancer with specificity. Eur J Pharmacol 2018;834:188-96.

135. Schweiger T, Hegedüs B, Nikolowsky C, et al. EGFR, BRAF and KRAS status in patients undergoing pulmonary metastasectomy from primary colorectal carcinoma: a prospective follow-up study. Ann Surg Oncol 2014;21:946-54.

136. Van der Jeught K, Xu HC, Li YJ, et al. Drug resistance and new therapies in colorectal cancer. World J Gastroenterol 2018;24:3834-48.

137. Couzin-Frankel J. Breakthrough of the year 2013. Cancer immunotherapy. Science 2013;342:1432-3.

138. Torino F, Corsello SM, Salvatori R. Endocrinological sideeffects of immune checkpoint inhibitors. Curr Opin Oncol 2016;28:278-87.
139. Tang J, Shalabi A, Hubbard-Lucey VM. Comprehensive analysis of the clinical immuno-oncology landscape. Ann Oncol 2018;29:84-91.

140. Morton DL, Hsueh EC, Essner R, et al. Prolonged survival of patients receiving active immunotherapy with Canvaxin therapeutic polyvalent vaccine after complete resection of melanoma metastatic to regional lymph nodes. Ann Surg 2002;236:438-48.

141. Morton DL, Mozzillo N, Thompson JF, et al. An international, randomized double-blind, phase 3 study of the specific active immunotherapy agent, Onamelatucel-L (Canvaxin $^{\mathrm{TM}}$ ), compared to placebo as a postsurgical adjuvant in AJCC stage IV melanoma. Presented at the Society of Surgical Oncology Annual Meeting;March 2326, 2006; San Diego, CA. Abstract 12.

142. Hoeller C, Michielin O, Ascierto PA, et al. Systematic review of the use of granulocyte-macrophage colonystimulating factor in patients with advanced melanoma. Cancer Immunol Immunother 2016;65:1015-34.

143. Nishijima TF, Deal AM, Williams GR, et al. Chemotherapy toxicity risk score for treatment decisions in older adults with advanced solid tumors. Oncologist 2018;23:573-9.

144. Kim JH. Chemotherapy for colorectal cancer in the elderly. World J Gastroenterol 2015;21:5158-66.

145. Morley JE, Vellas B, van Kan GA, et al. Frailty consensus: a call to action. J Am Med Dir Assoc 2013;14:392-7.

146. Charlson M, Szatrowski TP, Peterson J, et al. Validation of a combined comorbidity index. J Clin Epidemiol 1994;47:1245-51.

147. Mineo TC, Tamburini A, Perroni G, et al. 1000 cases of tubeless video-assisted thoracic surgery at the Rome Tor Vergata University. Future Oncol 2016;12:13-8.

148. Mineo TC, Sellitri F, Vanni G, et al.Immunological and inflammatory impact of non-Intubated lung metastasectomy. Int J Mol Sci 2017;18:7.

149. Vanni G, Tacconi F, Sellitri F, et al. Impact of awake videothoracoscopic surgery on postoperative lymphocyte responses. Ann Thorac Surg 2010;90:973-8.

150. Blackmon SH, Shah N, Roth JA, et al. Resection of pulmonary and extrapulmonary sarcomatous metastases is associated with long-term survival. Ann Thorac Surg. 2009;88:877-84.

151. Treasure T, Mineo TC, Ambrogi V, et al. Survival is higher after repeat lung metastasectomy than after a first metastasectomy: Too good to be true? J Thorac Cardiovasc 
Surg 2015;149:1249-52.

152. Glasziou P, Chalmers I, Rawlins M, et al. When are randomised trials unnecessary? Picking signal from noise. BMJ 2007;334:349-51.

153. Fiorentino F, Treasure T. Pulmonary metastasectomy for colorectal cancer: making the case for a randomized controlled trial in the zone of uncertainty. J Thorac Cardiovasc Surg 2013;146:748-52.

Cite this article as: Ambrogi V, Tamburrini A, Tajé R. Results of redo pulmonary metastasectomy. J Thorac Dis 2021;13(4):26692685. doi: $10.21037 /$ jtd-19-4064
154. Kirienko M, Cozzi L, Rossi A, et al. Ability of FDG PET and CT radiomics features to differentiate between primary and metastatic lung lesions. Eur J Nucl Med Mol Imaging 2018;45:1649-60.

155.Mineo TC, Pompeo E, Ambrogi V, et al. Video-assisted approach for transxiphoid bilateral lung metastasectomy. Ann Thorac Surg 1999;67:1808-10. 